\title{
THE CONNECTION BETWEEN STRATEGIC PLANNING AND PROGRAM BUDGETING IN THE DOMAIN OF CULTURE
}

\section{Danijela Janjić}

Poslovni i pravni fakultet, “Union-Nikola Tesla” Univerzitet, Beograd, Srbija

\section{Snežana Maksimović}

Poslovni i pravni fakultet, “Union-Nikola Tesla” Univerzitet, Beograd, Srbija

\section{Slavoljub Veselinović}

Kulturni centar Beograda, Beograd, Srbija

OMESTE

JEL category: M14, 022, P21

\section{Apstrakt}

$U$ radu se govori da su zakonskim uvođenjem budžeta po programskom modelu u sektoru kulture započete aktivnosti na unapređenju procesa planiranja unutar delatnosti kulture u celini i u pojedinim oblastima kulture (ustanovama kulture, pozorišnoj delatnosti, kinematografiji itd.). Razvoj i primena programskog budžetiranja u sektoru kulture je vrlo kompleksan zadatak sa mnogo problema, a najveći je zapravo nedostatak pravog znanja iz menadžmenta kulture i neprepoznavanje potrebe za njegovom primenom, ili nauke o organizaciji kulturnih delatnosti. Priprema budžeta po programskom modelu stvara potrebu posebnih istraživanja i analiza koji će definisati osnovne probleme ove specijalizovane menadžment discipline, kroz opisivanje $i$ istraživanje postojećih oblika organizovanja unutar kulturnih delatnosti, kao i razvijanje $i$ ispitivanje novih, adekvatnijih $i$ efikasnijih modela organizovanja. Na ovaj način koncipirano upravljanje ustanovama kulture treba da doprinese stvaranju uslova za kulturno stvaralaštvo i proizvodnju kulturnih dobara, za njihovo oblikovanje u dela koja su dostupna kulturnoj javnosti i za recepciju tih dela u kulturnoj javnosti. Na osnovu zaključaka o potencijalima i problemima kulturnog sektora date su preporuke za efikasnije, transparentnije i pravičnije upravljanje finansijama u sektoru kulture koje će poboljšati kontrolu tokova novca, unaprediti fiskalnu disciplinu i ojačati

Adresa autora zaduženog za korespodenciju: odgovornost u svim fazama budžetskog ciklusa.

Danijela Janjić

莑exluzive@yahoo.com 
Ključne reči: programsko budžetiranje, kulturni menadžment, indikatori kvaliteta, program, programska aktivnost, projekat

\begin{abstract}
The paper shows that the legal implementation of the program model budget in the culture sector started the activities for the planning process improvement in the domain of culture and in the certain fields of culture (cultural institutions, theater, cinematography etc.). The program budgeting development and implementation in the culture sector are very complex tasks with many issues, the major being the lack of adequate culture management knowledge and the disregarding of the need for its application, or the cultural activities organization science. The budget making per a program model requires special research and analyses which will define the basic problems of this specialized management discipline, through description and investigation of the existing organizational forms within culture activities, as well as development and investigation of new, more adequate and efficient organizing models. Thus, conceived cultural institutions management should contribute to enabling cultural creative work and cultural goods production, their formation into acts available to the cultural public and the reception of these acts in cultural public. Based on the conclusions on the culture sector potentials and problems the recommendations are given for a more efficient, more transparent and more just finance management in culture sector which will improve money flows control, advance the fiscal discipline and strengthen the responsibility in all phases of the budgetary cycle.
\end{abstract}

Keywords: program budgeting, culture management, quality indicators, program, program activity, project

\section{UVOD}

Kulturni resursi kojima raspolaže neka ustanova kulture na lokalnom ili nacionalnom nivou čine kapital - humani i kulturni, koji obezbeđuje društvu veliki broj pogodnosti tokom vremena. Ulaganje i unapređenje kulturnih resursa dovodi do stope prinosa koja se može valorizovati i u ekonomskom, društvenom i kulturnom pogledu. Ovako koncipirano izvršenje budžeta polazi od stanovišta da je i delatnost kulture sistem unutar koga se svesnom ljudskom delatnošću može oblikovati, obrazovati, uređivati, upravljati, usmeravati razvoj, zapravo unutar koga se mogu organizovati uslovi kulturnog stvaralaštva, oblici njegovog plasmana i prijema u najširoj javnosti (Dragićević-Šešić, \& Stojković, 2007).

Priprema budžeta kao operativnog plana po modelu programskog budžetiranja, u sektoru kulture nužno zahteva i primenu određenih instrumenata, koji stoje na raspolaganju kreatorima kulturne politike $u$ delatnostima kulture, usmerenim ka ciljevima i rezultatima koje treba ostvariti. Odlika ovog tipa budžetiranja je fokusiranje na planiranje programa i projekata koje treba ostvariti. Programski budžet (n.d., 2014) sastavlja se po programskoj klasifikaciji koja predstavlja prikaz programa, gde se rashodi i izdaci razvrstavaju prema glavnim programima i projektima kao skupovima aktivnosti koji su međusobno povezani i organizovani na takav način da vode ka ostvarenju određenog cilja. $U$ radu se posebno akcentira uloga indikatora (pokazatelja performansi) u procesu odlučivanja. Cilj rada jeste da se ispitaju faktori koji utiču na efikasnost i efektivnost merenja performansi i da se apostrofira veza između strategijskog planiranja i programskog budžetiranja u cilju olakšanja strategijski konzistentnog odlučivanja.

Unapređenje budžetskog procesa kroz programsko budžetiranje u sektoru kulture, predstavlja deo šire reforme upravljanja javnim finansijama, koje stavlja naglasak na utvrđivanje prioriteta i optimizaciju potrošnje kroz postojanje konkretnih programa, za koje su u budžetu odvojene konkretno određene sume novca, u cilju pružanja kvalitetnih usluga u delatnosti kulture. $\mathrm{Na}$ taj način vrši se usmeravanje sredstava na rešavanje konkretnih problema, čime se kreatorima kulturne politike omogućava da uspostave bolje odnose između resursa koji postoje u delatnostima kulture, strategija kulturnog razvoja, programa i rezultata koji treba da se postignu. Ovim modelom težište se stavlja na planiranje, odnosno očekivanje rezultata i praćenje šta je u prethodnim periodima postignuto 
sa odobrenim, odnosno iskorišćenim sredstvima. $\mathrm{U}$ radu će se primeniti kvalitativna metodologija, utemeljena na deskriptivnoj analizi istraživačkog problema, a sintetizovanjem različitih stavova izvešće se generalni zaključci za uticaj pojedinih faktora i uloga u procesu odlučivanja vezano za efektivnost sistema merenja performansi i njihovu povezanost sa konkretnim organizacionim faktorima u ustanovama kulture i opšte društvenim ciljevima u toj oblasti, nakon čega će se izvesti relevantni zaključci i ukazati na moguća ograničenja i buduće pravce razvoja.

\section{STRATEGIJSKO PLANIRANJE U OBLASTI KULTURE}

Uvođenje strateškog planiranja u ustanove kulture zahtev je savremenog vremena, koje kulturi nameće i potreba uspeha na tržištu, odnosno ekonomičnosti i efektivnosti poslovanja. Zakon o kulturi (Službeni Glasnik RS, 2009 i 2016) eksplicitno propisuje planiranje kulturnog razvoja na svim nivoima - državnom, pokrajinskom i nivou lokalne samouprave. Prema članu 7 ovog zakona država donosi strategiju za period od 10 godina, Pokrajina program, a lokalne samouprave svoje petogodišnje planove razvoja kulture. Zakon o kulturi definiše i načela kulturnog razvoja (član 3 ) i opšti interes u kulturi (član 6). U odsustvu nacionalne strategije razvoja i njome definisanih ciljeva, ovo bi moglo biti usmerenje prilikom formulisanja planova razvoja kulture na nižim nivoima vlasti, čime se istovremeno omogućava njihova usklađenost sa strategijom na nacionalnom nivou kada se bude formulisala i usvojila. Za izradu petogodišnjih planova razvoja kulture (u skladu sa Zakonom) potrebno je pravno utemeljene (normativni akt- odluka, rešenje) o pristupanju procesu planiranja, zatim je potrebno primeniti metodologiju prilagođenu oblasti kulture (Primer metodologije primenljiv na svaki kulturni sistem, bez obzira za koji nivo se planira, predstavlja Predlog strategije razvoja kulture u AP Vojvodini (2008-2015). Metodologija se zasniva na primeni naučnog metoda funkcionalne strateške analize (FSA) kao polazne osnove za izradu strateškog plana (Đukić, Dojčinović, Srećkov, \& Bosnić, 2007, str. 319-349) kojom se unutrašnji faktori kulturnih sistema kao što su porodice kulturnih sistema i njihovi akteri, resursi kojima određeni kulturni sistem raspolaže, kao i instrumenti koje donosioci odluka koriste u vođenju kulturne politike (kulturno nasleđe, izvođačke umetnosti, vizuelne umetnosti, kulturno obrazovna delatnost, amaterizam), sa posebnim akcentom na analizu međuresornih oblasti kulturne politike (umetničko obrazovanje, kulturni turizam, međunarodna saradnja).

Jedna od najčešće primenjivanih tehnika koja se koristi prilikom strateške analize je SWOT analiza. Da bi se ustanova kulture pozicionirala na tržištu i odredile njene unutrašnje snage i slabosti, kao i mogućnosti i pretnje koje joj dolaze iz okruženja, pored evaluiranja kulturne politike $\mathrm{i}$ poslovne filozofije-sada više ne samo njihove koherentnosti, već sasvim konkretnog strateškog značenja u određenom trenutku u određenoj sredini, potrebno je definisati i sve ostale faktore koji će biti podvrgnuti analizi, a to su različiti spoljni i unutrašnji faktori (Đukić, 2012, pp. 357-372).

Tek po završenoj strateškoj analizi, a na osnovu ocene zatečenog stanja, pristupa se kreiranju plana razvoja definisanjem vizije, misije, strateških ciljeva i prioriteta, kao i mera i aktivnosti koje treba preduzeti za njihovo ostvarenje. S obzirom na to da strateška analiza predstavlja bazu planiranja, samim tim znači da plan jasno proističe iz nje, da joj je kompatibilan, u smislu da se definišu mere $i$ aktivnosti za svaku od obuhvaćenih oblasti kulturne politike. Izrada akcionog plana sastavni je deo strateškog planiranja, pomoću koga će se strategije implementirati u praksi. Dugoročni razvoj planira se na osnovu potreba $\mathrm{i}$ potencijala, kao i sopstvenih mogućnosti i slabosti, ali uzimajući u obzir i prilike (spoljašnje faktore) koje je mogu ugroziti. Potrebno je da bude usklađen sa opštim interesom u kulturi, načelima kulturnog razvoja, postojećom zakonskom regulativom i nacionalnim i lokalnim strateškim dokumentima. Definisanim pravcima razvoja, a potom i njihovom implementacijom, kulturna politika postaje eksplicitna i ciljno orijentisana, na osnovu čega njeni rezultati postaju merljivi. $U$ tom smislu, za izradu programskog budžeta kao operativnog plana, akteri u oblasti kulture nužno moraju da primenjuju određene instrumente, odnosno alate strateškog planiranja. Kulturni razvoj $u$ savremenog doba zahteva uvođenje strateškog planiranja, koje prema prirodi svog delovanja pripada tzv. organizacionim, a prema smeru delovanja stimulativnim, podsticajnim 
instrumentom kulturne politike. Produkt strateškog procesa jeste dokument, dugoročni plan kojim su definisana ključna pitanja kulturnog života i kulturnog razvoja. Strateški plan sadrži idejni koncept kulturne politike, kao i plan potrebnih aktivnosti za njegovo ostvarenje. Za kreiranje nove poslovne politike sa definisanom vizijom i ciljevima kulturnog razvoja, odnosno definisanje očekivanih ishoda koji se mogu vrednovati u kontekstu različitih beneficija koje doprinose razvoju kulture i stvaranju kulturnih navika kod publike, neophodna su dva tipa istraživanja : Istraživanje u oblasti kulturnog menadžmenta (organizacioni nivo- na državnom, regionalnom ili lokalnom nivou); i Istraživanje publike i/ili ne-publike: analiza nivoa participacije različitih grupa u kulturnom životu zajednice (marketinška istraživanja publike).

Institucije kulture, stvaranjem nove poslovne politike kao polazna osnova pripreme za izradu programskog budžeta, treba da daju odgovore na sledeća pitanja:

- Kakva će biti nova programska orijentacija (programski profil, identitet...)

- Koliki će biti kvantitet programa

- Na koji način će se organizovati stvaranje kulturnog autputa

- Kakvi odnosi će se uspostavljati prema tržištu kulture

Strategija razvoja jedne ustanove uzima u obzir aktivnosti u celom socio-kulturnom području određenog sub-sistema kulture. Korišćenje svih raspoloživih podataka iz široko zasnovanih marketinških istraživanja, neophodno je u stvaranju programske i poslovne politike institucije kulture da bi ona bila konkurentna $u$ odnosu na ostatak kulturne ponude. Nakon definisane misije i izvršene strateške analize, neophodno je doneti dugoročne strateške ciljeve poslovne politike, a zatim postaviti konkretne godišnje ciljeve koji iz njih proizilaze. Dalje, akcionim planom predviđamo strategije i metode realizovanja programa aktivnosti kojima će se najefikasnije i najefektivnije postizati željeni ciljevi. Preciznim budžetom, sastavljenim od detaljno navedenih izdataka, ali i ciljanih prihoda, stvaraju se uslovi za kontrolu i evaluaciju stepena realizacije ciljeva već tokom prve godine primene programskog budžeta kao operativnog plana (Dragićevć-Šešić, \& Stojković, 2007, str.70-74)
STRATEŠKO PLANIRANJE

MISIJA - kulturna i poslovna politika

SWOT ANALIZA

DUGOROČNI STRATEŠKI CILJEVI

GODIŠNJI CILJEVI

AKCIONI PLAN I STRATEGIJE

BUDŽET

REALIZACIJA - organizovanje, kontrola, motivacija, koordinacija

EVALUACIJA

Merni indikatori

Kvalitativna analiza

Indikacije za sledeći ciklus strateškog planiranja

\section{DEFINISANJE USTANOVE KULTURE \\ BUDŽETA}

Programski budžet kao operativni plan, ne treba shvatiti samo kao "pravljenje novca" u oblasti kulture, već kao značajnu aktivnost koja doprinosi razvoju umetničke (kulturne) produkcije i stvaranju kulturnih navika kod publike. Budžet se koristi za planiranje rashoda i vodi ustanovu kulture kroz nastupajuću fiskalnu godinu, takođe služi kao osnova za finansijsko izveštavanje nadležnim institucijama i može se definisati kao moćan alat za raspodelu ograničenih resursa između konkurentnih prioriteta unutar programskih sadržaja - kulturnih potreba. Pošto potrebe uvek premašuju raspoloživa sredstva, sredstva koja dobije jedan organizacioni deo moraju biti odbijena od drugog dela. Vrednost sredstava koja se troše, mere se ne samo stečenim prednostima, nego i onim od čega se mora odustati, pa to znači da budžet predstavlja pravljenje ispravnih odabira. $U$ svom najjednostavnijem obliku, budžet se sastoji od detaljnog popisa predviđenih prihoda i predloženih rashoda za svaku kulturnu produkciju, za budućih dvanaest meseci, odnosno fiskalnu godinu. U idealnom slučaju, budžet predstavlja sveobuhvatnu raspodelu ograničenih resursa među potencijalnim organizacionim/ funkcionalnim delovima u kulturnim delatnostima.

Priprema budžeta po programskom modelu zahteva na prvom mestu da se detaljno ispitaju sve aktivnosti i projekti unutar ustanova kulture, da se proveri da li su u saglasnosti sa strateškim pravcima razvoja na državnom, odnosno na 
lokalnom nivou, te da se u skladu sa njima projektuju programi. Proces planiranja koji prethodi pripremi budžeta mora se zasnivati na temeljnoj analizi prethodnog perioda, to znači da se jasno utvrde trendovi iz prethodne godine i postave jasni kulturni, društveni i ekonomski ciljevi koji žele da se ostvare u sledećoj budžetskoj i najmanje $u$ dve naredne godine, koji treba da budu usaglašeni sa strategijom razvoja kulture na lokalnom i nacionalnom nivou. Sve to podrazumeva primenu jasne procedure ko radi, šta radi i u kom roku, to se takođe odnosi i na učešće građana, odnosno civilnog sektora, zapravo novi trend je da se preko transparentnog budžetskog procesa omogući da svi zainteresovani akteri daju svoj doprinos i sarađuju sa ključnim nosiocima / kreatorima kulturne politike pre svega na lokalnom nivou.

Podaci o budžetu treba da budu jasno predstavljeni sa opredeljenim programima i projektima koji imaju definisane zadatke i indikatore uspeha. Dosadašnji, linijski budžet usredsređen je na rashode na osnovu ekonomske klasifikacije i navodi koliko se sredstava izdvaja za svaku stavku koju organizacija kulture koristi. Rashodi su razdvojeni u više kategorija. Dakle, budžet po stavkama vodi evidenciju o tome koliko će se potrošiti i na šta će se potrošiti. lako je najjednostavniji za pripremu, ovakav budžet ne daje nikakve informacije o aktivnostima Ustanove kulture. Informacije o tome koliko je potrošeno za plate, materijal, održavanje i komunalije ne otkrivaju mnogo o stvarno pruženim uslugama. Npr. koliko građana je posetilo neku književnu tribinu, koje starosne dobi, nivoa obrazovanosti, ili koliko je karata prodato za neki koncert... Relativni nivo usluga i sredstava utrošenih na razne aktivnosti pokazuju gde su prioriteti. Ovaj budžet nudi i informacije pri odlučivanju jesu li prioriteti ispravni. Programski budžet razlikuje se od tradicionalnog (linijskog) pristupa $u$ : pripremi, pregledu i prezentiranju budžeta. Umesto fokusiranja na troškove, programski budžet je usmeren na očekivane rezultate usluga $i$ aktivnosti koje se sprovode. Naglasak je na postizanju dugoročnih ciljeva na nivou cele zajednice. $U$ programskom budžetu se prihodi $i$ rashodi povezuju $s$ višegodišnjim programima. Programski budžet utvrđuje očekivane rezultate i neposredne ishode tih ulaganja. Programski budžet je nastao kao rezultat pokušaja pronalaženja načina na koji bi se odabrale mogućnosti za pružanje usluga i odgovorilo na sledeća pitanja: Šta pokušavamo postići (dugoročni cilj) i koliko će koštati postizanje tog dugoročnog cilja. Uz pomoć programskog budžeta, usluge i aktivnosti subjekata kulture su organizovane po programima, određuju se mogućnosti za postizanje svakog planiranog cilja, zatim se određuje cena/korist za svaku mogućnost i konačno bira se najbolja mogućnost za odabrani program.

Pošto su važniji ukupni troškovi i rezultat nego cena pojedinih stavki, budžetska izdvajanja mogu se pratiti u obliku jednokratne isplate po programu, a ne po tradicionalnim stavkama. Time se menja tradicionalno praćenje linijskog budžeta, odnosno uspeh i rezultati se mere po definisanim programima. To znači da je važnost individualnih troškova zamenjena praćenjem troškova i programskih rezultata. Time, se isto tako menja priroda budžetskog izveštavanja. Izveštavanje po tipovima izdataka i organizacionim jedinicama postaje sekundarno, a izveštavanje po programima i njihovim nosiocima postaje primarno.

\section{FAZE PROGRAMSKOG BUDŽETA}

\subsection{Faza planiranja}

U ovoj fazi treba utvrditi listu potreba i prioriteta, zatim definisati ciljeve koji treba da se postignu u dugoročnom periodu. Tim za implementaciju predlaže aktivnosti koje treba da omoguće jednake mogućnosti za sve subjekte u kulturi, ustanove, udruženja građana, da vode upravljačke strukture ka odgovornom finansiranju, koje će doprinositi zadovoljavanju različitih potreba i ostvarivanju ciljeva za svaku od navedenih oblasti, poštujući principe i vrednosti definisane strategijom. Osnovni cilj planiranja i pripreme programskog budžeta je povećanje efikasnosti. U fazi planiranja treba dogovoriti na sledeća pitanja: šta je delokrug poslova subjekta kulture, da li su ti poslovi stalnog karaktera ili su vezani za određeni vremenski period, koliki su ukupni troškovi da se nameravana aktivnost sprovede, koji su rezultati, odnosno efektikulturni, društveni, ekonomski. 


\subsection{Faza programiranja}

$\mathrm{U}$ ovoj fazi se definisane aktivnosti i grupišu u programe ili projekte preko kojih će ciljevi biti realizovani. Koncepcija strateškog razvoja takođe treba da se uvek uzima u obzir u procesu donošenja odluka, tako da svaki program odnosno projekat bude u skladu sa osnovnom poslovnom i kulturnom politikom odgovarajuće institucije.

U fazi programiranja obezbeđuju se informacije za svaki od odobrenih programa u poređenju sa stvarnim rashodima prethodne godine, sa procenama za naredne dve godine, ažuriranom procenom za tekuću budžetsku godinu i u skladu sa gornjim granicama rashoda subjekata kultureodobrenim aproprijacijama od nadležnog Ministarstva/lokalne samouprave.

Faza programiranja uključuje i Pripremanje budžetskog kalendara kojim se utvrđuju postupci i raspored koje će subjekat kulture slediti u razvoju budžeta i pomaže u pripremi i pravovremenom donošenju budžeta. Treba imati u vidu da je srednjoročni okvir budžeta zasnovan na "prenosnom" trogodišnjem planu budžeta, što znači da je polazna tačka za izradu budžeta naredne fiskalne godine prva projektovana godina u okviru prethodno odobrenog dokumenta okvirnog budžeta. U skladu sa nacrtom srednjoročnog plana subjekti kulture mogu predložiti realokaciju planiranih sredstava u postojećoj programskoj strukturi. U tom koraku mogu se "ugasiti" neadekvatne ili neefikasne programske aktivnosti ili projekti, koji se dostavljaju nadležnom ministarstvu u okviru procedure za utvrđivanje prioritetnih oblasti finansiranja.

\subsection{Faza budžetiranja}

Ova faza ima operativan karakter i integriše raspoloživa finansijska sredstva sa ciljevima i aktivnostima radi iznalaženja najboljeg rešenja. Programski ciljevi predstavljaju specifične rezultate koji treba da odrede šta će biti ostvareno, za koga i do kojeg datuma (povećati izdavačku aktivnost za $25 \%$ ). Dokumentacija programskog budžeta institucija kulture predstavlja određenu kulturnu politiku i jasnu zamisao menadžmenta čija koherentnost treba da odgovori na sledeća ključna pitanja:
- Zašto postoji vaša institucija? (Svrha ili misija subjekta kulture)

- Odnosu institucije prema kulturi i umetničkom stvaralaštvu

- Stav institucije prema publici (važnost "lojalnosti" i stalnosti publike)

- Koje rezultate Vaša institucija želi da postigne? (Strateški ciljevi subjekta kulture)

- Šta vaša institucija radi kako bi postigla rezultate? (Programi i operativni ciljevi subjekta kulture)

- Koliko to košta? (Sredstva koja su potrebna subjektu kulture da bi postigao svoje operativne ciljeve, podeljene po programima i ekonomskim kategorijama)

- Kako meriti rezultate onoga što radite? (Mere i ciljevi učinka subjekta kulture)

- Ko je odgovoran za rezultate programa? (Rukovodilac programa)

Ova pitanja su osnova za pripremu programskog budžeta, ukoliko subjekat kulture može na njih da odgovori spreman je za izradu programskog budžeta.

U fazi budžetiranja troškovi funkcionisanja subjekta kulture primarno se iskazuju po konkretnim programima i aktivnostima uz pomoć programsko budžetsko računovodstvene klasifikacije. Primena funkcionalne i ekonomske klasifikacije ima sekundarni značaj u sistemu. Aproprijacije u budžetu odražavaće ukupnu masu sredstava, čija je potrošnja vezana za realizaciju jednog programa ili projekta. Budžetski program bi trebalo da bude sadržan iz sledećih elemenata:

- Naziv ili šifra programa (Npr. - Otvorenost i dostupnost ustanova kulture)

- Naziv subjekata kulture, kao i ime, prezime i funkcija lica koje je odgovorno za realizaciju programa (Npr. Centar za kulturu grada Beograda).

- Ključni ciljevi, kratak opis i vremensko trajanje programa (Npr. Ostvarivanje saradnje sa obrazovnim ustanovama i civilnim sektorom).

- Ostali elementi programa (pravni osnov, prioritet programa, rizici ostvarenja programa,, izvori verifikacije programa i sl.).

- Budžet programa

- Prikaz strukture aktivnosti budžetskog korisnika 
- Vrednost projekata kojima se realizuje program

- Očekivani rezultati programa

Najjednostavniji način prelaska sa linijskog na programski budžet, bar u prvim godinama implementacije programskog budžeta, moguće je uraditi zadržavanjem postojeće organizacione strukture koja će biti dopunjena programima i programskim aktivnostima.

Organizaciona klasifikacija bi zadržala dominantnu ulogu prilikom izrade odluke o budžetu - u tom kontekstu bi pomirili postojeći način rada sa zakonskom obavezom. To je svakako najbolje rešenje koje će se vremenom menjati i unapređivati. Jednostavno rečeno, budžetski korisnici će zadržati odluke kakve su imali, ali će u okviru postojeće strukture da ubacuju programske aktivnosti. Pošto će organizaciona klasifikacija biti dominantna, potrebno je da odluka o budžetu sadrži i rekapitulaciju programa i programskih aktivnosti koja bi uključivala i definisane ciljeve i indikatore.

S obzirom da član 28. Zakona o budžetskom sistemu predviđa postojanje dva dela budžeta: opšteg i posebnog, preporuka je da programski deo bude u posebnom delu iskazan po programskoj klasifikaciji kojom se prikazuju ciljevi, očekivani rezultati, aktivnosti i sredstva potrebna za ostvarivanje navedenih ciljeva.

Potrebno je pratiti sledeći princip izrade Odluke o budžetu:

- Organizaciona klasifikacija (budžetski korisnik), zatim ispod toga program, pa programska aktivnost, zatim

- funkcionalna klasifikacija i na kraju izvori finansiranja (izvori su po istoj logici kao i do sada)

Isto važi za projekat: budžetski korisnik program- projekat- izvori finansiranja. Treba imati na umu da su programska aktivnost $i$ projekat $u$ istom rangu i da zajedno čine program. To znači da projekat nije deo programske aktivnosti, već deo programa. Programske aktivnosti u okviru pojedinih programa počinju rečima "funkcionisanje" ili "upravljanje, što znači da troškove plata i stalne troškove, kao i sve troškove neophodne za rad treba evidentirati u okviru ovih programskih aktivnosti. Ostale programske aktivnosti sadržaće troškove koji se odnose na sprovođenje aktivnosti, odnosno delatnosti zbog koje subjekat kulture postoji. Prilikom izdvajanja i posebnog prikaza jednog projekata, treba imati u vidu definicije projekta, a odnose se na ograničeno vreme trajanja u smislu roka, početka i završetka itd.). "Projekat može biti investicioni, ali i tekući (razne manifestacije). Programske kategorije raspoređene su u dva hijerarhijska nivoa. Na višem nivou su programi, a na nižem su programske aktivnosti i projekti koji im pripadaju. Što znači, nosilac troškova su budžetski programi i projekti na koje se vrši alociranje aktivnosti $\mathrm{i}$ troškova radi ostvarenja određenog cilja.

Program je jednostavno grupisanje sličnih aktivnosti ili usluga koje obavlja kulturni centar kako bi postigao svoj strateški cilj ili ciljeve. Programi se utvrđuju u skladu sa ključnim nadležnostima $i$, u meri u kojoj je to moguće, ostvaruje se njihova veza sa organizacionom strukturom da bi se obezbedila primena principa organizacione odgovornosti nad sprovođenjem programa. Model kulturnog centra zasniva se na koncepciji koja podjednak značaj daje difuziji (prikazivanju) vrhunskih dela umetničkog stvaralaštva, podsticanju stvaralaštva, ali i animaciji i edukaciji stanovništva (socio-kulturna funkcija). Difuzija kulture, kao osnovni zadatak institucije kulture predstavlja izbor i selekciju sadržaja i predstavljanje kulturnih dobara lokalne, nacionalne i svetske kulturne baštine. Jedan od glavnih zadatka rukovodstva institucija kulture jesu kriterijumi za izradu i vrednovanje programa. $\mathrm{Ti}$ kriterijumi se razlikuju od organizaciono programskog modela. Umetnička i stručna vrednost programa ima odlučujući značaj $u$ velikim prestižnim kulturnim centrima, pluralizam pristupa je primeren u opštinskim, a participacija (učešće publike) u malim specifičnim kulturnim centrima i onim namenjenim posebnim društvenim grupama. Ipak, mogu se postaviti određeni opšti kriterijumi, na osnovu kojih se mogu objektivno analizirati realni dometi rada kulturnog centra. Funkcija kulturnog centra se ne iscrpljuje u podsticanju stvaralaštva i prikazivanju - difuziji kulturnih dobara; centar mora da bude žarište kulturnog života jedne sredine, da utiče i usmerava sadržajima svog rada život $u$ svakodnevnici. Kulturni centri obično imaju sledeće sektore: pozorišni, filmski, muzički, 
književni, likovni, kulturološki, naučni i društveno politički. Oni različitim programskim aktivnostima obavljaju sva tri pomenuta cilja: stvaralaštvo, animaciju i difuziju. Jedan od glavnih zadataka kolegijuma organizacija kulture su kriterijumi za izradu i evaluaciju programa. Kriterijumi se razlikuju u zavisnosti od organizaciono programskih modela kulturnih centara, ipak mogu se postaviti opšti kriterijumi, na osnovu kojih se mogu objektivno analizirati rezultati kulturnih centara. Jedan od osnovnih kriterijuma je podsticanje stvaralaštva. Analizom Beogradskih kulturnih centra došlo se do zaključka da svaki podstiče samo razvoj određene grane umetničkog stvaralaštva, ili određene starosne grupe, okupljajući oko sebe bilo amatere, bilo profesionalce. Valorizacija ostvarenih rezultata može da se vrši upućivanjem realizovanih umetničkih ostvarenja na odgovarajuće događaje ili festival, zatim ocenom kritike, ili ocenom publike.

Bitan kriterijum za ocenu uspešnosti jednog kulturnog centra je umetnička, naučna ili stručna (edukativna, animacijska) vrednost programa. Odjek svakog programa u javnosti odnosi se uvek na umetničku ili stručnu vrednost, ali i na originalnost, neuobičajenost programa, kompleksnost načina i metode prezentacije programa. Zatim, informativnost programa je značajan kriterijum koji ne predstavlja samo animacioni faktor (propaganda) već ima i edukativni značaj, jer dublje, sadržajnije upoznaje posetioce i potencijalne posetioce sa programima, njihovim estetskim i drugim vrednostima. Participacija, učešće publike kao kriterijum za vrednovanje kulturnog centra ne sme da se uzima samo u formi kvantitativnog pokazatelja, već i kao kvalitativni kriterijum (stvarno učešće publike u odvijanju određenog programa). Težnja za brojnom publikom jeste značajna, ali isti broj posetilaca filma i tribine ima sasvim različita značenja i pruža informacije o različitom uspehu tih programa. Zaštita kulturne baštine je poseban kriterijum jer kulturu ne čini samo savremeno stvaralaštvo već i kulturna dobra nastala tokom istorije. Ne sme se izostaviti kao poseban kriterijum za vrednovanje rada jednog kulturnog centra ni njegovo učešće u kulturnom turizmu, jer su na mapama turističkih ponuda često i određeni muzeji, a prema istraživanjima postoje interesovanja za saznavanja o prošlosti kroz uvide u dokumenta, video projekcije, težnja ka upoznavanju druge kulture, takođe negovanje interkulturalnosti daje osnov za komparaciju sa pojavama u današnjem vremenu.

Projekat je vremenski ograničena ideja kulturne organizacije čijim sprovođenjem se postižu ciljevi koji doprinose postizanju ciljeva programa. Osnovni oblici projekata u kulturi su: izložba, koncert, predstava, tribina (predavanja, književno veče, promocija) priredba (kontakt program) filmska ili video projekcija. Kompleksni oblici projekata su : manifestacije (festivali, smotre, sajmovi), radionice, animacione forme. Mas medijski projekti u kulturi su: radio emisije, TV emisije, tekstovi u štampi i dr. Postoje osnovne, zajedničke karakteristike svakog projekta, bez obzira na njegovu konceptualnu suštinu, a to su: svaki projekat je orijentisan ka ostvarenju određenog cilja, projekat podrazumeva preduzimanje međusobno povezanih akcija koje imaju precizno određeno trajanje (početak i kraj), projekat karakteriše posebnost i jedinstvenost, po sebi predstavlja određeni rezultat, odnosno cilj. Operacionalizacija ideje je osnovno područje projektnog menadžmenta. U ovoj fazi neophodno je definisati smisao projekta i njegove osnovne ciljeve. $\mathrm{Da}$ bi pristupili realizaciji projekta neophodno je da se pribave sredstva fandreising projekta. Slede realizacija i kontrola tokom trajanja projekta i na kraju evaluacija (trenutkom završetka projekta - premijerom ili zatvaranjem izložbe, ne prestaje rad na projektu). Ciljevi evaluacije su da proceni, sistemski i objektivno koliko je to moguće, relevantnost projekta za kulturni i umetnički život sredine u kojoj je projekat nastao i bio realizovan. Bitno je istaći da se evaluacija kulturno umetničkih projekata odnosi na kvalitet programa projekta $\mathrm{i}$ njegovu efektivnost, a takođe i na efikasnost menadžmenta i postignutu ekonomičnost projekta. $U$ evaluaciji programa uzimaju se $u$ obzir: umetničko-estetske vrednosti programa, kulturološki kvalitet programa (inovativnost $u$ pristupu, metodu...) kvantitet i balans programa u odnosu na planirani, efekat na primarne ciljne grupe (analiza publike), efekti na sekundarne ciljne grupe (analiza medijskog odjeka i PR delatnosti), ostvarivanje specifičnih ciljeva projekata. Evaluacija menadžmenta odnosi se na: planiranje (vremensku efikasnost - način korišćenja vremena), budžetski balans (cost- 
effectiveness), raznovrsnost izvora finansiranja, sigurnost izvora, timski rad I njegovu efikasnost, doprinos članova tima.

\subsection{Utvrđivanje indikatora programa za sektor kulture}

Pojam indikatora ili pokazatelja je intuitivno jasan, međutim formalna definicija nije toliko jednostavna. Indikatori su empirijski podaci kvalitativne i kvantitativne prirode. Ovi podaci postaju pokazatelji performansi ukoliko izražavaju zamišljene ciljeve učesnika u nekom procesu. To im daje kontekstualni i vremenski značaj (Tung, Baird, \& Schoch, 2011). Indikatori upravljačkim strukturama u organizacijama kulture moraju pružiti relevantne informacije u vezi sa različitim aspektima strateškog planiranja kako bi se mere prilagodile internim ciljevima i zahtevima koje društvo stavlja pred institucije kulture. Definisanjem indikatora odrađen je samo jedan deo pripreme za izradu programskog budžeta u ustanovi kulture. Svaka ustanova kulture trebalo bi na odgovarajući način da odredi skup indikatora i definiše postupke prikupljanja neophodnih podataka. Osim toga, potrebno je odrediti referentne vrednosti ("benchmarks") u cilju primene dobijenih rezultata na planiranje aktivnosti u narednom periodu. Indikatori se odabiraju za različite svrhe. Za praćenje postizanja utvrđenog cilja programa koriste se indikatori ishoda, koji su u direktnoj vezi sa tim ishodom. Indikatori učinka definišu se kao kvantitativne i trajne mere izlaznih rezultata, krajnjih rezultata $\mathrm{i}$ efikasnosti javnog sektora. (Adler, 2011). Pružaju osnove za merenje rezultata programa, aktivnosti i resursa dodeljenih za ove programe. Ne postoji jedinstven postupak koji bi definisao kako, koliko i na koji način odabrati skup indikatora. S obzirom da svaki pokazatelj treba da bude u vezi sa ciljem ili namerom, te s obzirom na šarolikost učesnika i perspektiva koje srećemo u institucionalnim okvirima u oblasti kulture postavlja se pitanje: Da Ii indikatori zaista mere ono što treba da mere? Stoga je neophodno razmotriti sledeće važne aspekte:

- U koju svrhu (svrhe) i iz koje perspektive su odabrani indikatori?

- Kako i putem kojeg procesa se indikatori odabiraju?
- Kako oceniti njihovu reprezentativnost i validnost?

- Da li su indikatori pouzdani u smislu da ista vrednost ukazuje na isto stanje stvari?

- Šta su uzroci povećavanja i smanjivanja izlaznih vrednosti pokazatelja? U kojoj meri je to rezultat prethodno primenjenih mera?

Ključna pitanja jesu reprezentativnost i validnost. U kojoj meri pokazatelj meri ono što treba da meri? Za primenu indikatora potrebne su sve vrste statistike, ali je teško donositi zaključke o kvalitetu na osnovu kvantiteta. Zato se mora uložiti napor da se uoče operativni signali koji sadrže različite kvalitativne aspekte posmatranog problema. Srbija do sada nije pristupila sistemskom definisanju indikatora u sektoru kulture. Prvi iskorak u definisanju indikatora za praćenje stanja u kulturu učinjen je u Odeljku Izveštaja o kreativnoj ekonomiji 2013- Posebno izdanje Širenje staza lokalnog razvoja u kome su date smernice- Kako meriti i podsticati kreativni razvoj na lokalnom nivou. U ovom pristupu prikazani su indikatori kreativnih industrija grupisani $u$ tri celine: resursi, kapaciteti i učinci. Resursi kao neophodni kapital, kapaciteti kao infrastrukturna podrška resursima i učinci kao krajnji ishod ulaganja $u$ kapacitete i resurse predstavljaju sveobuhvatne elemente za istraživanje kulturnog sektora. Ovako grupisani i pobrojani indikatori se ne moraju u potpunosti koristiti već in treba selektivno primenjivati u zavisnosti od strukture određene mikro sredine koja se istražuje (Izveštaj o kreativnoj ekonomiji, Program UNDP \& UNESCO, 2013). U tom smislu, ulaganje $u$ održavanje i unapređivanje kulturnih resursa kojima raspolaže neki grad ili region čini kapital koji se može valorizovati u ekonomskom, društvenom i kulturnom pogledu, a može se klasifikovati u pet kategorija: kreativna radna snaga, kreativna preduzeća, institucije kulture, baština, nematerijalna kulturna baština.

Sektor kulture zavisi od infrastrukture kao i bilo koji drugi sektor. Ovi kapaciteti se odnose na stepen privatne i javne podrške i njihovog učešća u kulturnim aktivnostima, nivoima socijalnog kapitala koji je akumuliran unutar zajednice, institucijama civilnog društva, kapacitetima obrazovnog sistema u generisanju kulturnih vrednosti, značaja medija i komunikacione infrastrukture u procesu pružanja podrške 
kulturnoj produkciji, distribuciji i potrošnji. Bilo koji program ili projekat koji podrazumeva ulaganje u neki od aspekata kreativne ekonomije bi trebalo da se zasniva na postizanju određene stope prinosa koja se može valorizovati u ekonomskom ili u nekom drugom izvedenom ishodu. Rezultati i njihovi indikatori mogu biti grupisani u sledeće četiri kategorije održivog razvoja:

Ekonomski: rezultat od primarnog značaja može biti podsticaj lokalnoj ekonomiji generisan od strane kulturnih institucija:

- Obim i vrednost lokalne proizvodnje kulturnih dobara (broj predstava, broj posetilaca, izvoz u druge regione, izvoz u druge zemlje...

- Manifestacije koje stimulišu kulturnu privlačnost grada

- Privlačenje poslovnih investicija

- Broj prodatih ulaznica u lokalitetima kulturne baštine

- Kulturne ture.

Društveni indikatori koji pokazuju da kreativna ekonomija može da doprinese promociji interkulturnog dijaloga, poštovanju kulturnih identiteta, zaštiti ljudskih prava, obrazovanju:

Obeležja kulturnog identiteta jedinstvenih za grad, region...

- Platforma za među etničke kontakte (udeo različitih etničkih grupa, promocije manifestacija na različitim jezicima...)

- Nediskriminisanje žena na kulturnoj bazi

- Sloboda izražavanja

- Rezultati u oblasti obrazovanja (broj dece koja učestvuju u dodatnim aktivnostima iz oblasti umetnosti, broj umetnika koji rade kao nastavnici u školama, broj studenata koji diplomiraju na umetničkim akademijama)

Kulturni: unapređenje društvenog blagostanja kroz aktivno učešće građana u umetničkoj i kulturnoj potrošnji; produkciji i participaciji:

- Broj posetilaca po tipu događaja-institucija

- Broj posetilaca (manifestacija-institucija) procentualno izražen u odnosu na ukupan broj stanovnika

- Sastar publike (prema polu, starosti, obrazovanju...)

- Broj građana koji se aktivno uključuju u rad institucija (kreativno pisanje, amatersko pozorište, pravljenje muzike...)

- Volontiranje
- Vreme posvećeno kulturnim aktivnostima (pasivna potrošnja, aktivna participacija)

- Razvoj umetničkih formi (produkcije novih radova, inovativna upotreba novih medija)

- Novi načini izražavanja kulturnog identiteta

- Briga o kulturnim veštinama

- Razmene umetnika sa inostranstvom, zastupljenost domaćih umetnika na sajmovima u inostranstvu, kulturno brendiranje...

Ekološki indikatori u ovoj kategoriji, naglašavaju značaj veze između kulture i životne sredine $u$ smislu održivog razvoja:

- izložbe u funkciji podizanja svesti o pitanjima zaštite životne sredine, drame, filmski, televizijski sadržaji društvenih medija koji prenose ekološke poruke

- ekološki svesni principi dizajna za potrebe pozorišta

- energetska efikasnost u radu I održavanju prostora ustanova kulture

- demonstracija odgovornosti za zaštitu životne sredine u kreativnim praksama

Ekonomski ishodi u ovom kontekstu mogu biti generisani u sledeće kategorije:

- autput kulturnih dobara i usluga (obim vrednosti kulturnih dobara)

- vrednost i dodata vrednost kulturne produkcije

- zapošljavanje (broj novootvorenih radnih mesta za umetnike i kreativne radnike)

- izvoz (obim i vrednost izvoza kulturnih dobara u usluga - distribucija unutar države i u druge zemlje)

- poslovni razvoj (stvaranje kreativnih klastera i sl.)

- turizam (uticaj kulturnih institucija na privlačenje turista)

- ekonomske inicijative obezbeđivanja ravnopravnog učešća u kulturi i zadovoljavanju kulturnih potreba

Da bi opstali u uslovima savremenog dinamičnog i turbulentnog okruženja, subjekti kulture moraju identifikovati svoje postojeće pozicije, pojasniti svoje ciljeve i delovati na što efikasniji i efektivniji način. Sistemi merenja indikatora upravo ovo omogućavaju. Efektivan sistem merenja performansi omogućava organizacijama kulture da procene da li su njihovi kratkoročni i dugoročni 
ciljevi ostvareni i da li je došlo do napretka u društvenom smislu u celini u skladu sa definisanom strategijom. Treba napomenuti da se uvažavaju kako finansijski, tako i nefinansijski indikatori koji odražavaju efekte ključnih aktivnosti koji dodaju vrednost organizacije kulture u celini.

Sistemi merenja performansi treba uglavnom da se koriste kao alat upravljanja u cilju motivacije, implementacije strategije i ostvarenja ciljeva, tj. kao instrumentarijum strategijske kontrole i kontrole upravljanja (Domanović, 2013, pp. 4144). Dobar okvir za merenje učinka /indikatora performansi sadrži tri ključna elementa:

Jasno iskazani ciljevi: Šta ustanova kulture želi da postigne nekim programom? Gde i kako želi da ostvari pozitivne promene?

Model logičkog okvira (log-frame) koji obezbeđuje kompletno mapiranje ulaznih veličina (inputa) preko procesa / aktivnosti do izlaznih veličina (autputa) a zatim i uspostavljanje veze sa ostvarenjem planiranih (neposrednih, posrednih i krajnjih ciljeva).

Dinamika i plan realizacije čime se objašnjava kako model logičkog okvira evoluira od sadašnjeg stanja, preko neposrednih i prelaznih rezultata, do konačnih ishoda koji se često ostvaruju tek mnogo godina kasnije. To omogućava sadržajno praćenje ostvarenja ciljeva primenom efektivnog sistema za monitoring i evaluaciju.

\section{PROCES MONITORINGA EVALUACIJA POSTIGNUTOG}

Monitoring- praćenje napretka. Proces kojim se prikupljaju i pružaju informacije o sprovođenju programa, programskih aktivnosti i projekata $u$ odnosu na očekivane rezultate (indikatore). Uključuju izveštavanje i obrazloženje odstupanja od cilja.

Evaluacija - analiza izmerenih vrednosti na osnovu indikatora kao i relevantnost mera koje se sprovode. Evaluaciju sprovodi sam korisnik, ali i spoljni nezavisni subjekt (sveobuhvatna costbenefit analiza). Ocena efektivnosti i efikasnosti, odnosno uspeha programa, programskih aktivnosti i projekata. Sveobuhvatnija analiza veze između primene merenja performansi i efektivnosti, u ustanovama kulture daje uvid u preovlađujuće organizacione uslove koji bi mogli da povećaju/ ugroze efektivnost. Podrška upravljačkim strukturama u nameri da se ostvare željeni ishodi performansi povezana je sa obukama radnika u kulturi da bi sa jedne strane zaposleni u kulturi bili svesni potrebe da se fokusiraju na različite aspekte efektivnosti sistema, sa druge strane da se istraživačima pruži novo merilo za procenu efektivnosti. Međutim, kada je oblast kulture u pitanju planeri i zaposleni u kulturi nailaze na teškoću koja se sastoji u izmirenju ciljeva kvalitativnog karaktera i strategija koje se zasnivaju na kvantitativnom ocenjivanju tih ciljeva i sredstava koje treba upotrebiti da bi se ti ciljevi postigli. Potrebno je određeni umetnički kvalitet razmatrati sa stanovišta kvantiteta, što je teško pomiriti sa stanovišta umetnika i sa stanovišta ljubitelja umetnosti. Jednom rečju treba da budemo u stanju da odredimo kojom kombinacijom sredstava obezbeđujemo najbolji učinak kada su u pitanju ciljevi koje želimo postići. Iz svega navedenog proizilazi da su potrebne sveobuhvatne analize u svakoj pojedinoj oblasti kulture, kao i u jednom opštem celovitom pogledu na kulturni sektor, da bi njegova uloga koja je značajna sa stanovišta kvaliteta, postala vidljiva $i$ očigledna zahvaljujući ciframa i podacima koji se mogu upoređivati sa istim sektorima $u$ drugim sredinama. Takođe, povezivanje svih zainteresovanih aktera $u$ javnom, privatnom i civilnom sektoru i uvođenje mešovitog finansiranja, dovelo bi do veće autonomije $u$ odlučivanju javnih regionalnih i lokalnih institucija.

\section{OBAVEZE IZVEŠTAVANJA REZULTATIMA}

Neki subjekti kulture će smatrati da su na neki način „različiti“ i da nije moguće meriti njihov rezultat. Međutim, ako se ne može izmeriti rezultat nekog programa ili aktivnosti kako je onda moguće upravljati istim? Ukoliko se stvarni uspeh projekta ili rezultati ne mogu demonstrirati, kako onda opravdati dalje zahteve za budžetskim sredstvima. Ukoliko se ne može meriti neka aktivnost u kulturi, da li će neko primetiti kada će ta aktivnost da se završi? Iz svih ovim pitanja, proizilazi zaključak da je za subjekte kulture najvažnije da odaberu prave indikatore (mere performansi) koji treba da budu relevantni $u$ pogledu strateških ciljeva subjekata kulture i operativnih ciljeva programa, i da budu korisni u pogledu merenja uspeha ili napretka u skladu sa tim ciljevima. Merenje kvaliteta izlaznog rezultata 
je još izazovniji zadatak i može zahtevati sofisticiranije i skuplje tehnike, poput anketa za ispitivanje zadovoljstva klijenata, tako da se u prvim fazama izrade indikatora preporučuje da se fokusiraju na razvoj dobrih mera kvantiteta i kvaliteta izlaznog rezultata.

Osnovna svrha izvršenja budžeta je izdvajanje sredstava odobrenih prema usvojenom budžetu i praćenje njihove potrošnje. Kada subjekti kulture budu određivali mere izlaznog rezultata i prikupljali informacije o njima, uprava će koristiti te informacije za lakše donošenje odluka o raspodeli budžetskih sredstava. Nadležni ne mogu dozvoliti da se sredstva troše na neefikasne ili neefektivne programe ili usluge. Takođe, subjekti kulture će dobijene informacije o učinku i očekivanim rezultatima koristiti kako bi opravdali nove predloge pre svega visoko prioritetne potrošnje i za nastavak postojećih programa. U tom smislu, budžet treba posmatrati u višegodišnjem kontekstu. Budžet prethodne i tekuće godine pomaže u proceni prihoda i rashoda sledeće fiskalne godine i nivoima troškova jednog programa. Treba napomenuti da ponekad i spoljni faktori mogu da utiču na učinak programa, odnosno da dovedu do rezultata manjih od očekivanih (npr. kvalitetne aktivnosti isključi na letnjim scenama mogu ostati bez efekta zbog vremenskih nepogoda itd.). Iz svega navedenog, jasno je da problem budžetiranja i finansiranja kulturnih aktivnosti nameće potrebu da se stalno unapređuju uporedna istraživanja kulture. Do razrađenih kriterijuma za poređenje može se doći zapravo samo kroz takva uporedna istraživanja. Ti kriterijumi treba da iskažu, uporedo sa izmenama u potrebama u pojedinim kulturama i nužno različitim kulturnim i društvenim ciljevima, različitosti ne samo među pojedinim društvima, nego i među pojedinim istorijskim fazama razvoja jednog istog društva. $\mathrm{Na}$ osnovu takvih kriterijuma moguće bi bilo razraditi sistem merenja koji bi smanjio ulogu subjektivnih procena $u$ kom stepenu je recimo potrebna komercijalizacija kulture, a u kome nekomercijalizovani oblici kulturnih aktivnosti, zatim obim u kome su finansirana i pod kolikom su kontrolom države sredstva masovne komunikacije itd., naročito prilikom poređenja koja se u oblasti kulture vrše na međunarodnom planu.

\section{ZAKLJUČAK}

Upravljanje subjektima kulture $u$ sadašnjim društvenim uslovima nameće potrebu za kvantitativnim pregledom finansiranja kulture, kao i varijacija zavisnih od strukture finansiranja, iako je veoma teško kvantifikovati izlazni rezultat u ovom sektoru. U tom smislu, neophodno je da se definišu mere i aktivnosti za svaku od obuhvaćenih oblasti kulture čime kulturna politika postaje eksplicitna i ciljno orijentisana, na osnovu čega njeni rezultati postaju merljivi. Na taj način organi upravljanja subjektima kulture koristeći svoja zakonska, politička i finansijska ovlašćenja odgovaraju na konkretne potrebe jedne sredine i uspostavljaju određene kulturne vrednosti i istovremeno stvaraju ambijent koji je stimulativan svim akterima tog kulturnog sistema.

Ovaj rad daje smernice za upravljačke organe u oblastima kulture, akcenat se stavlja na stratešku analizu kojom se definišu potrebe i potencijali, kao i sopstvene mogućnosti i slabosti uzimajući u obzir i spoljašnje faktore koji je mogu ugroziti. Potrebno je da planiranje bude usklađeno sa opštim interesom u kulturi, načelima kulturnog razvoja, postojećom zakonskom regulativom, nacionalnim i lokalnim strateškim dokumentima uz ocenu zatečenog stanja i uvažavanje osnovnog strateškog pravca Srbije ka članstvu u Evropskoj uniji. To znači da je potrebno poznavati osnovne razvojne trendove i principe na kojima počivaju i razvijaju se savremene kulturne politike evropskih zemalja (participacija, inkluzivnost, decentralizacija, promocija savremenog stvaralaštva, očuvanje kulturnog nasleđa $\mathrm{i} d r$ ). Ovo upravo odgovara principu supsidijarnosti koji je afirmisao Ugovor iz Mastrihta, a koji predviđa da donošenje odluka treba da se odvija što je moguće bliže građanima, čime se ide u susret zadovoljavanju njihovih potreba. $U$ drugom delu rada ukazuje se da reforma sistema budžetiranja podrazumeva odgovarajuću posvećenost i dugotrajno ulaganje u kadrove u cilju ostvarenja boljih organizacionih performansi. Povezanost merila performansi i organizacionih faktora sa efektivnošću sistema pruža uvid u preovlađujuće organizacione uslove koji podržavaju ostvarenje željenih ciljeva. Istraživanje ukazuje da je pristup zasnovan na indikatorima osnov objektivne procene, a osim toga koristi se za identifikaciju slabosti čije otklanjanje je neophodno ako se želi 
da se resursi kulture koriste za poboljšanje izlaznih rezultata u ekonomskom ili opšte društvenom smislu. Takođe, preliminarne uporedne informacije iz različitih zemalja su neophodne da bi se povećala uopštenost zaključaka, tako da bi buduća istraživanja mogla da se fokusiraju na ulogu instrumenata kulturne politike i kolika je uloga stručnjaka u procesima odlučivanja u drugim zemljama, kako bi se osigurao kvalitet i transparentnost procesa odlučivanja i smanjio rizik politizacije prilikom donošenja odluka značajnih za razvoj kulture.

\section{CITIRANI RADOVI}

Adler, R. (2011). Performance management and organizational strategy: how to design systems that meet the needs of confrontation strategy firms. The British Accounting Review, 43, pp. 251-263

Domanović, V. (2013). Efektivnost sistema merenja performansi u uslovim savremenog poslovnog okruženja, Kragujevac: Ekonomski horizonti,

Dragićević-Šešić, M., \& Stojković, B. (2007). Kultura, menadžment, animacija, marketing, Beograd: Clio, pp. $72-79$

Đukić, V. (2012). Država i kultura - studije savremene kulturne politike. Beograd: Fakultet dramskih umetnosti u Beogradu, pp. 448.

Đukić Dojčinović, V., Srećkov, D., \& Bosnić, D. (2007). Strateška analiza kao osnova strateškog planiranja razvoja kulture u AP Vojvodini. Beograd: Zbornik radova Fakulteta dramskih umetnosti, 11-12, pp. 319-349

n.d. (2004). Predlog strategije razvoja kulture u AP Vojvodini (2008-2015)

n.d. (2014, Feb). Uputstvo za izradu programskog budžeta. Ministarstvo Finansija Republike Srbije. Preuzeto http://www.skgo.org/files/fck/File/2015/PB2016/Uputstvo\%20za\%20izradu\%20programskog\% 20budzeta.pdf

Tung, A. Baird. K., \& Schoch, P.H. (2011). Factors influencing the effectiveness of performance measurement systems. International Journal of Operations \&Production Management, 31(12), 1287-1310.

Zakon o budžetskom sistemu (Službeni glasnik RS, br.54/09,73/10,101/10,101/11,93/12, 62/13, 63/13, -ispravka 108/13, 142/14, 68/15, - dr. zakon 103/15)

Zakon o kulturi (Službeni glasnik RS, br. 72/09, 13/2016, 30/2016 ispravka)

UNDP \& UNESCO (2013). Izveštaj o kreativnoj ekonomiji (Creative Economy Report). Preuzeto sa http://www.unesco.org/culture/pdf/creative-economy-report-2013-en.pdf

Datum prve prijave:

05.04.2016.

Datum prijema korigovanog članka: $\quad$ 25.04.2017.

Datum prihvatanja članka:

24.06.2017.

\section{Kako citirati ovaj rad? / How to cite this article?}

Style - APA Sixth Edition:

Janjić, D., Maksimović, S., \& Veselinović, S. (2017, July 15). Povezanost strategijskog planiranja i programskog budžetiranja u oblasti kulture. (Z. Čekerevac, Ed.) FBIM Transactions, 5(2), 4356. doi:10.12709/fbim.05.05.02.05 
Style - Chicago Sixteenth Edition:

Janjić, Danijela, Snežana Maksimović, and Slavoljub Veselinović. "Povezanost strategijskog planiranja i programskog budžetiranja u oblasti kulture." Edited by Zoran Čekerevac. FBIM Transactions (MESTE) 5, no. 2 (July 2017): 43-56.

Style - GOST Name Sort:

Janjić Danijela, Maksimović Snežana and Veselinović Slavoljub Povezanost strategijskog planiranja i programskog budžetiranja u oblasti kulture [Journal] // FBIM Transactions / ed. Čekerevac Zoran. - Belgrade - Toronto : MESTE, July 15, 2017. - 2 : Vol. 5. - pp. 43-56.

Style - Harvard Anglia:

Janjić, D., Maksimović, S. \& Veselinović, S., 2017. Povezanost strategijskog planiranja i programskog budžetiranja u oblasti kulture. FBIM Transactions, 15 July, 5(2), pp. 43-56.

Style - ISO 690 Numerical Reference:

Povezanost strategijskog planiranja i programskog budžetiranja u oblasti kulture. Janjić, Danijela, Maksimović, Snežana and Veselinović, Slavoljub. [ed.] Zoran Čekerevac. 2, Belgrade - Toronto: MESTE, July 15, 2017, FBIM Transactions, Vol. 5, pp. 43-56. 